\title{
Risk factors associated with fatal pulmonary hemorrhage in locally advanced non-small cell lung cancer treated with chemoradiotherapy
}

\author{
Masami Ito ${ }^{1}$, Seiji Niho ${ }^{1 *}$, Keiji Nihei $^{2}$, Kiyotaka Yoh ${ }^{1}$, Hironobu Ohmatsu ${ }^{1}$ and Yuichiro Ohe
}

\begin{abstract}
Background: The purpose of this study was to identify the risk factors associated with fatal pulmonary hemorrhage $(\mathrm{PH})$ in patients with locally advanced non-small cell lung cancer (NSCLC), treated with chemoradiotherapy.

Methods: The medical records of 583 patients with locally advanced NSCLC, who were treated with chemoradiotherapy between July 1992 and December 2009 were reviewed. Fatal PH was defined as PH leading to death within $24 \mathrm{~h}$ of its onset. Tumor cavitation size was defined by the cavitation diameter/tumor diameter ratio and was classified as minimum $(<0.25)$, minor $(\geq 0.25$, but $<0.5)$, and major $(\geq 0.5)$.

Results: Of the 583 patients, $2.1 \%$ suffered a fatal PH. The numbers of patients with minimum, minor, and major cavitations were 13, 11, and 14, respectively. Among the 38 patients with tumor cavitation, all 3 patients who developed fatal PH had major cavitations. On multivariate analysis, the presence of baseline major cavitation (odds ratio, 17.878), and a squamous cell histology (odds ratio, 5.491) proved to be independent significant risk factors for fatal PH. Interestingly, all patients with fatal PH and baseline major cavitation were found to have tumors with squamous cell histology, and the occurrence of fatal PH in patients having both risk factors was 33.3\%.
\end{abstract}

Conclusions: Patients at high risk of fatal PH could be identified using a combination of independent risk factors.

\section{Background}

Clinical trials have shown that properly chosen candidates with locally advanced non-small cell lung cancer (NSCLC) have a survival advantage when treated with chemoradiotherapy, which is now a widely used mode of treatment for such patients $[1,2]$.

Massive pulmonary hemorrhage $(\mathrm{PH})$ is one of the most serious events observed in patients with lung cancer treated with chemotherapy and/or radiotherapy, and is now highlighted by the introduction of bevacizumab (Avastin; Genentech, South San Francisco, CA, USA), which induce a high incidence of massive $\mathrm{PH}$ in a subset of patients. Although several studies have evaluated risk factors that are suggested to be associated with the development of a massive $\mathrm{PH}$ in the setting of endobronchial brachytherapy or bevacizumab therapy [3-7],

\footnotetext{
* Correspondence: siniho@east.ncc.go.jp

'Department of Thoracic Oncology, National Cancer Center Hospital East,

Kashiwa, Chiba, Japan

Full list of author information is available at the end of the article
}

these reports included relatively small numbers of patients or had results that lacked sufficient statistical power. In addition, no previous reports have evaluated the risk factors of massive $\mathrm{PH}$ in the setting of chemoradiotherapy.

In the present report, we reviewed a large series of consecutive patients with locally advanced NSCLC treated with chemoradiotherapy. The purpose of this study was to identify risk factors associated with fatal $\mathrm{PH}$ in these patients.

\section{Methods \\ Patients}

A total of 598 patients with stage II and III NSCLC, treated with chemoradiotherapy between July 1992 and December 2009 were identified in our departmental database. Fifteen patients were excluded because a pretherapy chest computed tomography $(\mathrm{CT})$ scan was not available. The remaining 583 patients comprised the study cohort. Fatal PH, defined as a PH leading to death 
within $24 \mathrm{~h}$ of its onset, was determined by reviewing medical records. $\mathrm{PH}$ events that were possibly caused by an additional complicating factor such as disease progression were excluded.

\section{Radiographic tumor characteristics}

Chest CT scans of all patients were assessed by a physician blinded to the clinical history and patient status. The presence and size of the cavitation as well as the longest diameter of the largest tumor mass were evaluated as potentially relevant baseline tumor characteristics. Cavitation size was defined as the cavitation diameter/ tumor diameter ratio and was classified as minimum $(<$ $0.25)$, minor $(\geq 0.25$ but $<0.5)$, or major $(\geq 0.5)$.

\section{Clinicopathological information}

We reviewed the regularly updated clinical database of each patient for the following clinicopathological information: age (below or above 70 years), gender, Eastern Cooperative Oncology Group performance status $(0,1$, or 2), smoking history (nonsmokers or ever-smokers), TNM stage, tumor location (central or peripheral), tumor laterality (right or left), baseline chest pain (presence or absence), baseline cough (presence or absence), and baseline hemoptysis (presence or absence). We included age in the analysis using 70 years as a cut-off to provide the information on elderly patients, because 70 years is widely accepted as a cut-off point for defining the elderly population [8]. Disease stages was based on the TNM classification of the International Union Against Cancer, 6th edition [9]. We defined peripheral tumors as those in which the center of the mass was within the parenchyma and had no or minimal contact with hilar structures. Other tumors were labeled central tumors.

\section{Pathological evaluation}

We reviewed the medical records of each patient for information on tumor pathology. Histological type was determined according to the World Health Organization classification [10].

\section{Statistical analysis}

For univariate analyses, variables were evaluated using Fisher's exact test. For multivariate analysis, logistic regression was used to identify independent risk factors related to the incidence of fatal $\mathrm{PH}$. All $\mathrm{p}$ values reported were 2-sided, and the significance level was set at less than 0.05 . Analyses were performed using the statistical software SPSS 11.0 (Dr. SPSS II for Windows, standard version 11.0; SPSS Inc., Chicago, IL, USA). This study was conducted as part of a National Cancer Center institutional review board-approved protocol.

\section{Results}

Table 1 shows the clinicopathological characteristics of 583 patients with locally advanced NSCLC. The patient cohort consisted of 482 (82.7\%) men and 101 (17.3\%) women. Their age range was 31-85 years with a median of 65 years. The most predominant histological type was adenocarcinoma $(275 ; 47.2 \%)$, followed by squamous cell carcinoma (208; 35.7\%). Of the 583 patients, 12 (2.1\%) patients developed fatal $\mathrm{PH}$. Centrally located tumors were seen in 127 (21.8\%) patients. Baseline tumor cavitation was detected in 38 (6.5\%) patients.

Table 2 shows the incidence of fatal $\mathrm{PH}$ and cavitation diameter/tumor diameter ratio in 38 patients with baseline tumor cavitation. The number of patients with minimum, minor, and major cavitations were 14, 11, and 13, respectively. Among the patients with cavitation, all 3 patients with fatal $\mathrm{PH}$ had major cavitations.

On univariate analysis, squamous cell histology, a centrally located tumor, and the presence of a major cavitation proved to be significant risk factors for fatal $\mathrm{PH}$ (Table 3). On multivariate analysis, squamous histology (odds ratio [OR], 5.491; $p=0.040$; 95\% confidence interval $[\mathrm{CI}], 1.079-27.943)$ and the presence of baseline tumor cavitation (OR, 17.878; $p=0.001$; 95\% CI, 3.43093.190) were shown to be independent significant risk factors for fatal PH (Table 4).

The association between tumor histological type and the incidence of fatal PH among the patients with baseline major cavitation $(\mathrm{n}=14)$ is shown in Table 5 . Among the 14 patients with baseline major cavitation, fatal PH occurred in 3, all of whom had squamous cell carcinomas. The incidence of fatal $\mathrm{PH}$ in patients with both baseline major cavitation and squamous cell histology was $3 / 9(33.3 \%)$.

\section{Discussion}

The treatment of locally advanced NSCLC remains controversial [11] due to the heterogeneity of this patient population. Surgery alone is not recommended as the standard therapy, because the prognosis of these patients varies according to the status of mediastinal lymph node involvement. Additionally, primary surgery has been shown to have poor outcomes in certain subgroups of patients with this disease [12]. The most common treatment approaches are concurrent chemoradiation (CRT) $[13,14]$, or in some cases trimodality therapy, which involves CRT followed by surgical resection $[15,16]$. Thoracic irradiation may cause a bronchovascular fistula, which results either from the rapid regression of the tumor or from necrosis of the bronchial mucosa and the vessel wall by radiotherapy itself with the attendant endothelial damage causing vascular abnormalities. As the pathogenesis of $\mathrm{PH}$ involves 
Table 1 Clinicopathological characteristics of 583 patients treated with chemoradiotherapy

\begin{tabular}{|c|c|c|}
\hline Characteristics & & No. of patients (\%) \\
\hline Overall number & & 583 \\
\hline \multirow[t]{3}{*}{ Age (years) } & median (range) & $65(31-85)$ \\
\hline & $\leq 70$ & $449(77.0)$ \\
\hline & $>70$ & $134(23.0)$ \\
\hline \multicolumn{3}{|l|}{ Gender } \\
\hline & Male & $482(82.7)$ \\
\hline & Female & $101(17.3)$ \\
\hline \multicolumn{3}{|l|}{ ECOG PS } \\
\hline & 0 & $171(29.3)$ \\
\hline & 1 & $408(70.0)$ \\
\hline & 2 & $4(0.7)$ \\
\hline \multicolumn{3}{|l|}{ Smoking history } \\
\hline & Nonsmoker & $51(8.7)$ \\
\hline & Ever-smoker & $532(91.3)$ \\
\hline \multicolumn{3}{|l|}{ Stage } \\
\hline & $\| A$ & $6(1.0)$ \\
\hline & $\| \mathrm{B}$ & $24(4.1)$ \\
\hline & IIIA & $209(35.8)$ \\
\hline & $\| \mathrm{IIB}$ & $344(59.0)$ \\
\hline \multicolumn{3}{|l|}{ Histology } \\
\hline & Adenocarcinoma & $275(47.2)$ \\
\hline & Squamous cell carcinoma & $208(35.7)$ \\
\hline & NSCLC & $98(16.8)$ \\
\hline \multicolumn{3}{|c|}{ Fatal pulmonary hemorrhage } \\
\hline & Absent & $571(97.9)$ \\
\hline & Present & $12(2.1)$ \\
\hline \multicolumn{3}{|l|}{ Tumor loction } \\
\hline & Central & $127(21.8)$ \\
\hline & Peripheral & $456(78.2)$ \\
\hline \multicolumn{3}{|l|}{ Tumor laterality } \\
\hline & Right & $346(59.3)$ \\
\hline & Left & $236(40.5)$ \\
\hline \multicolumn{3}{|c|}{ Baseline tumor cavitation } \\
\hline & Absent & $545(93.5)$ \\
\hline & Present & $38(6.5)$ \\
\hline \multicolumn{3}{|l|}{ Baseline cough } \\
\hline & Absent & $317(54.4)$ \\
\hline & Present & $266(45.6)$ \\
\hline \multicolumn{3}{|c|}{ Baseline chest pain } \\
\hline & Absent & $484(83.0)$ \\
\hline & Present & $99(17.0)$ \\
\hline \multicolumn{3}{|l|}{ Baseline sputum } \\
\hline & Absent & $454(77.9)$ \\
\hline & Present & $129(22.1)$ \\
\hline \multicolumn{3}{|c|}{ Baseline hoarseness } \\
\hline & Absent & $536(91.9)$ \\
\hline & Present & $47(8.1)$ \\
\hline \multicolumn{3}{|c|}{ Baseline hemoptysis } \\
\hline & Absent & $468(80.3)$ \\
\hline & Present & 115 (19.7) \\
\hline
\end{tabular}

ECOG PS: Eastern Cooperative Oncology Group Performance Status, NSCLC: non-small cell lung cancer 
Table 2 Incidence of fatal PH by baseline tumor cavitation diameter/tumor diameter ratio

\begin{tabular}{ccc}
\hline & \multicolumn{2}{c}{ No. of patients $(\mathbf{n}=\mathbf{3 8})$} \\
\cline { 2 - 3 } Cavitation diameter/tumor diameter & Non-fatal $\mathbf{P H}$ & Fatal $\mathbf{P H}$ \\
\hline$\geq 0.5$ & 11 & 3 \\
$\geq 0.25$, but $<0.5$ & 11 & 0 \\
$<0.25$ & 13 & 0 \\
\hline
\end{tabular}

$\mathrm{PH}:$ pulmonary hemorrhage

bronchovascular fistulae and vascular abnormalities [5,17], thoracic irradiation is a potential cause of $\mathrm{PH}$, and its toxicity may be enhanced when combined with chemotherapy [18].

This study was conducted to identify the risk factors for fatal PH in patients with locally advanced NSCLC treated with chemoradiotherapy. Risk factors for fatal $\mathrm{PH}$ in this set of patients have not yet been established. In the current study, risk factors were determined by multiple logistic regression of variables that included patient demographics, baseline hemoptysis, tumor location, histological type, and baseline tumor cavitation, all of which could influence the occurrence of $\mathrm{PH}$. We identified 2 independent significant risk factors for fatal $\mathrm{PH}$ : the presence of baseline major cavitation and squamous cell histology. The presence of baseline major cavitation proved to be a powerful risk factor (OR, 17.878) for fatal PH. Chaudhuri et al. examined cavitating lung cancer and reported that vascular invasion by tumor cells causes intratumoral ischemia [19], which induces hypoxia-inducible transcription factors and several angiogenic factors such as vascular endothelial growth factors [20]. The mechanism of $\mathrm{PH}$ in tumors with cavitation remains unclear, but disruption of the abnormal intratumoral vasculature by these transcription factors or cytokines may be one of the causes of $\mathrm{PH}$ in case of tumors with cavitation.

While the incidence of $\mathrm{PH}$ appeared to be high in patients with squamous cell carcinoma, it remains unclear whether squamous cell carcinoma contributed directly to the hemorrhage. For example, the risk of $\mathrm{PH}$ observed in the first phase I clinical trial of bevacizumab rendered antiangiogenic therapies inaccessible to patients with squamous cell carcinoma; [21] nevertheless, bevacizumab was added to standard frontline chemotherapy for NSCLC and has shown a survival benefit in these patients compared to chemotherapy alone $[22,23]$. However, it was not clear whether histology alone was the central risk factor for $\mathrm{PH}$ since squamous cell tumors differed from adenocarcinomas in that they were more frequently centrally located and had a greater tendency to cavitate. In the current study, we showed that squamous cell histology was associated with $\mathrm{PH}$, independent of tumor location or the presence of cavitation.
Table 3 Correlation between fatal PH and pathological characteristics

\begin{tabular}{|c|c|c|c|c|}
\hline \multirow{2}{*}{\multicolumn{2}{|c|}{ Characteristics }} & \multicolumn{2}{|c|}{ No. of patients (\%) } & \multirow{2}{*}{$\begin{array}{c}P \\
\text { valuet }\end{array}$} \\
\hline & & $\begin{array}{c}\text { Non-fatal } \\
\text { PH }\end{array}$ & $\begin{array}{c}\text { Fatal } \\
\mathrm{PH}\end{array}$ & \\
\hline \multicolumn{2}{|c|}{ Overall number } & 571 & $12(2.1)$ & \\
\hline \multirow[t]{3}{*}{ Age (y) } & median (range) & $65(31$ & & \\
\hline & $\leq 70$ & $437(76.5)$ & $12(100)$ & 0.078 \\
\hline & $>70$ & $134(23.5)$ & $0(0)$ & \\
\hline \multicolumn{5}{|l|}{ Gender } \\
\hline & Male & $472(82.7)$ & $10(83.3)$ & 1.000 \\
\hline & Female & 99 (17.3) & $2(16.7)$ & \\
\hline \multicolumn{5}{|c|}{ ECOG PS } \\
\hline & 0 & $170(29.8)$ & $1(8.3)$ & 0.196 \\
\hline & 1,2 & $401(70.2)$ & $11(91.7)$ & \\
\hline \multicolumn{5}{|c|}{ Smoking history } \\
\hline & Non smoker & $51(8.9)$ & $0(0)$ & 0.613 \\
\hline & Ever-smoker & $520(91.1)$ & $12(100)$ & \\
\hline \multicolumn{5}{|c|}{ Histology } \\
\hline & $\begin{array}{l}\text { Squamous cell } \\
\text { carcinoma }\end{array}$ & $198(34.7)$ & $10(83.3)$ & $<0.001^{*}$ \\
\hline & Nonsquamous NSCLC & $373(65.3)$ & $2(16.7)$ & \\
\hline \multicolumn{5}{|c|}{ TNM stage } \\
\hline & $\|$ & $30(5.3)$ & $0(0)$ & 1.000 \\
\hline & III & $541(94.7)$ & $12(100)$ & \\
\hline \multicolumn{5}{|c|}{ Tumor laterality } \\
\hline & Right & $341(59.7)$ & $5(41.7)$ & 0.242 \\
\hline & Left & $230(40.3)$ & $7(58.3)$ & \\
\hline \multicolumn{5}{|c|}{ Tumor location } \\
\hline & Central & $121(21.2)$ & $6(50.0)$ & $0.028^{*}$ \\
\hline & Peripheral & $450(78.8)$ & $6(50.0)$ & \\
\hline \multicolumn{5}{|c|}{ Major cavitation } \\
\hline & Absent & $560(98.1)$ & $9(75.0)$ & $<0.001^{*}$ \\
\hline & Present & $11(1.9)$ & $3(25.0)$ & \\
\hline \multicolumn{5}{|c|}{ Baseline cough } \\
\hline & Absent & $313(54.8)$ & $4(33.3)$ & 0.155 \\
\hline & Present & $258(45.2)$ & $8(66.7)$ & \\
\hline \multicolumn{5}{|c|}{ Baseline chest pain } \\
\hline & Absent & $475(83.2)$ & $9(75.0)$ & 0.438 \\
\hline & Present & $96(16.8)$ & $3(25.0)$ & \\
\hline \multicolumn{5}{|c|}{ Baseline hemoptysis } \\
\hline & Absent & $458(80.2)$ & $10(83.3)$ & 1.000 \\
\hline & Present & $113(19.8)$ & $2(16.7)$ & \\
\hline
\end{tabular}

* indicates significance, +Fisher's exact test, PH: pulmonary hemorrhage, ECOG PS: Eastern Cooperative Oncology Group Performance Status, NSCLC: nonsmall cell lung cancer, Major cavitation is defined as its cavitation/tumor diameter ratio $\geq 0.5$

Interestingly, the tumors of all patients with fatal $\mathrm{PH}$ who had major tumor cavitation before treatment had squamous cell histology. The incidence of fatal $\mathrm{PH}$ in patients having both risk factors, baseline major cavitation and squamous cell histology, was $33.3 \%$; in contrast, the overall incidence in the study cohort was $2.1 \%$. This 
Table 4 Multivariate analysis of risk factors for fatal pulmonary hemorrhage

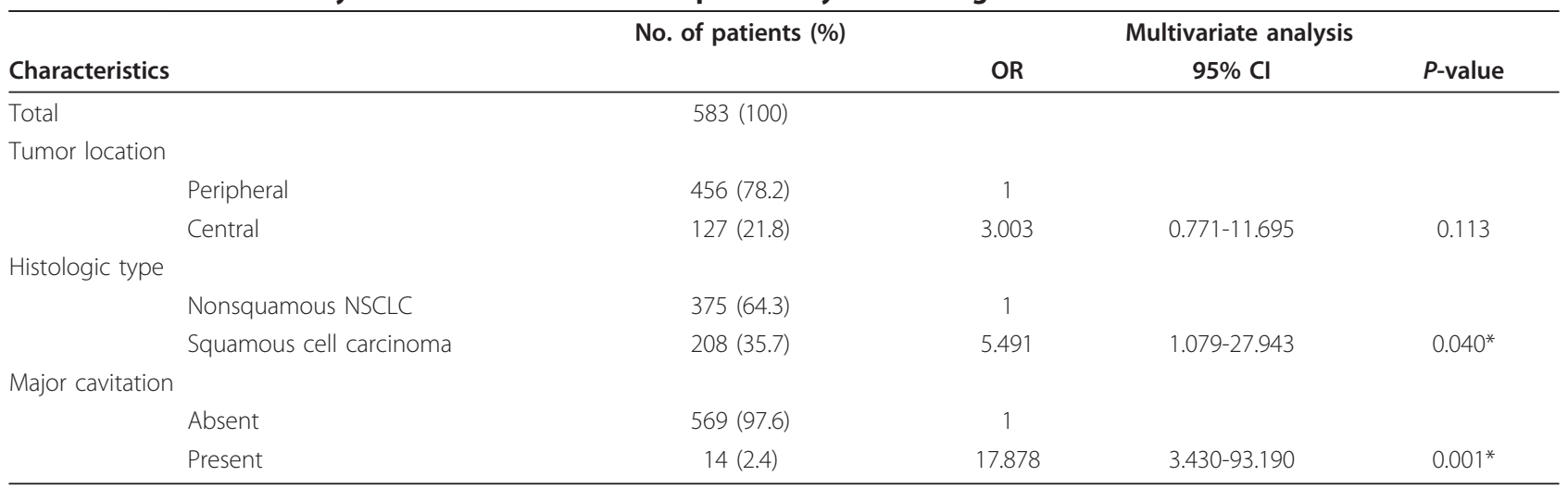

OR: odds ratio, $\mathrm{Cl}$ : confidence interval, ${ }^{*}$ indicates significance, NSCLC: non-small cell lung cancer

findings shows that use of a combination of independent significant risk factors may enable the identification of patients at high risk of fatal $\mathrm{PH}$.

Considering the risk factors for fatal $\mathrm{PH}$ identified here, primary surgery may be one of the treatment options for patients with operable locally advanced NSCLC, with baseline major cavitation and squamous cell histology. For the management of massive and recurrent hemoptysis, bronchial artery embolization (BAE) is also a demonstrated treatment option [24-31]; however, the bleeding recurrence rate among patients with BAE-treated lung cancer can reach 50\% [32]. Surgical intervention, in contrast, is curative [33] and an established treatment for PH. A surgical approach may be beneficial for these patients at high risk of fatal $\mathrm{PH}$ with regard to local control of the potential source of the hemorrhage. In addition, although it remains unclear whether chemoradiation contributes directly to the occurrence of fatal PH in this study, primary surgical resection may help avoid potentially unfavorable primary chemoradiation.

The present study was retrospective and had limitations. It was not designed to evaluate the association between therapeutic modality and fatal $\mathrm{PH}$ risk. To our knowledge, no definitive information evaluates the direct association between therapeutic modality and fatal $\mathrm{PH}$ risk. Accordingly, it remains unclear which therapeutic modality among surgery, chemotherapy, and

Table 5 Association between tumor histology and incidence of fatal PH among patients with baseline major cavitation $(\mathbf{n}=\mathbf{1 4})$

\begin{tabular}{lcc}
\hline \multirow{2}{*}{ Histology } & \multicolumn{2}{c}{ No. of patients (\%) } \\
\cline { 2 - 3 } Overall number & Non-fatal PH & Fatal PH \\
Adenocarcinoma & 11 & 3 \\
Squamous cell carcinoma & $5(100)$ & $0(0)$ \\
\hline
\end{tabular}

radiotherapy should be selected for patients identified as being at high risk of fatal $\mathrm{PH}$ in our study. We consider primary surgery to be a potential treatment option for patients with operable locally advanced NSCLC, who have both baseline major cavitation and squamous cell histology. However, further studies are required to compare the risk of surgery and the risk of fatal $\mathrm{PH}$ that accompanies chemotherapy or radiotherapy. Additionally, a considerable number of patients with locally advanced NSCLC are inoperable. For these patients, further studies are required in order to compare the differences between therapeutic modalities with regard to treatment benefit and the risk of fatal $\mathrm{PH}$ accompanying each therapy. Furthermore, since patients with fatal $\mathrm{PH}$ were all $\leq 70$ years of age or had stage III tumors, we could not evaluate the correlation between age or stage and risk of fatal PH in this study. Despite these limitations, this is the first study to identify the statistically significant independent risk factors for fatal $\mathrm{PH}$ in patients with locally advanced NSCLC treated with chemoradiotherapy. We believe that our data will be helpful for future trials and for clinicians when determining therapeutic strategies for patients with locally advanced NSCLC.

\section{Conclusions}

$\mathrm{PH}$ is a rare but life-threatening event that occurs in NSCLC. Patients at high risk of fatal PH may be identified by a combination of the independent risk factorsmajor baseline cavitation and squamous cell histology.

\section{Abbreviations}

NSCLC: Non-small cell lung cancer; PH: Pulmonary hemorrhage; $C T$ : Computed tomography; Cl: Confidence interval; CRT: Chemoradiation; BAE: Bronchial artery embolization.

\section{Acknowledgements}

This work was supported in part by the Grant-in-Aid for Cancer Research from the Ministry of Health, Labour and Welfare, the Grant for Scientific

Research Expenses for Health Labour and Welfare Programs, the Foundation 
for the Promotion of Cancer Research, 3rd-Term Comprehensive 10-year Strategy for Cancer Control, and Special Coordination Funds for Promoting Science and Technology from the Ministry of Education, Culture, Sports, Science and Technology, the Japanese Government.

\section{Author details}

'Department of Thoracic Oncology, National Cancer Center Hospital East, Kashiwa, Chiba, Japan. ${ }^{2}$ Department of Radiation Oncology, National Cancer Center Hospital East, Kashiwa, Chiba, Japan.

\section{Authors' contributions}

$\mathrm{Ml}$ contributed to the design and coordination of the study, performed the statistical analysis, prepared the manuscript, and read and approved the final manuscript. SN contributed to the design and coordination of the study, revised the article for important intellectual content, and read and approved the final manuscript. $\mathrm{KH}, \mathrm{KY}, \mathrm{HO}$, and $\mathrm{YO}$ contributed to preparing the manuscript, and read and approved the final manuscript.

\section{Competing interests}

The authors declare that they have no competing interests.

Received: 1 October 2011 Accepted: 20 January 2012

Published: 20 January 2012

\section{References}

1. Dillman RO, Herndon J, Seagren SL, et al: Improved survival in stage III non-small cell lung cancer: seven-year follow-up of Cancer and Leukemia Group B (CALGB) 8433 trial. J Natl Canc 1996, 88:1210-1215.

2. Sause WT, Scott $C$, Taylor $S$, et al: Radiation Therapy Oncology Group (RTOG) 88-08 and Eastern Cooperative Oncology Group (ECOG) 4588: preliminary results of a phase III trial in regionally advanced, unresectable non-small cell lung cancer. J Natl Cancer Ins 1995, 87:198-205.

3. Sandler $A B$, Schiller JH, Gray R, et al: Retrospective evaluation of the clinical and radiographic risk factors associated with severe pulmonary hemorrhage in first-line advanced resectable non-small-cell lung cancer treated with Carboplatin and Paclitaxel plus bevacizumab. J Clin Oncol 2009, 27:1405-1412, Epub 2009 Feb 17. Erratum in: J Clin Oncol, 2009, 27 (20):3410.

4. Panos RJ, Barr LF, Walsh TJ, et al: Factors associated with fatal hemoptysis in cancer patients. Chest 1998, 94(5):1008-1013.

5. Isaacs RD, Wattie WJ, Wells AU, et al: Massive haemoptysis as a late consequence of pulmonary irradiation. Thorax 1987, 42(1):77-78.

6. Makker HK, Barnes PC: Fatal haemoptysis from the pulmonary artery as a late complication of pulmonary irradiation. Thorax 1991, 46(8):609-610.

7. Miller RR, McGregor DH: Hemorrhage from carcinoma of the lung. Cancer 1980, 46(1):200-205.

8. Balducci L: Geriatric oncology: challenges for the new century. Eur J Cancer 2000, 36(14):1741-1754.

9. In UICC: TNM Classification of Malignant Tumors. 6 edition. Edited by: Sobin LH, Wittekind CH. New York: Wiley; 2002:99-103.

10. Travis WD, Brambilla E, Muller-Hermelink HK, et al: World Health Organization Classification of Tumors: Pathology and Genetics of Tumors of the Lung, Pleura, Thymus and Heart Lyon: IARC; 2004.

11. Friedel G, Budach W, Dippon J, et al: Phase II trial of a trimodality regimen for stage III non-small-cell lung cancer using chemotherapy as induction treatment with concurrent hyperfractionated chemoradiation with carboplatin and paclitaxel followed by subsequent resection: a single-center study. J Clin Oncol 2010, 28(6):942-948, Epub 2010 Jan 25

12. Robinson LA, Ruckdeschel JC, Wagner $\mathrm{H} \mathrm{Jr}$, et al: American College of Chest Physicians. Treatment of non-small cell lung cancer-stage IIIA: ACCP evidence-based clinical practice guidelined. Chest , 2 2007, 132(Suppl 3):243S-265S.

13. Mantel N: Evaluation of survival data and two new rank order statistics arising in its consideration. Cancer Chemother Rep 1996, 50:163-170.

14. Friedel $G$, Linder $A$, Weigang $S$, et al: The surgical treatment of stage III (N2). In Recent advances in lung cancer. Edited by: Carpagnano F, De Lena M. Milan: Masson; 1995:119-127.

15. Hata $\mathrm{E}$, Miyamoto $H$, Tanaka $M$, et al: The necessity of extended systemic dissection of the regional lymph node in radical operation for lung cancer. Kyobu Geka 1994, 47(1):40-44.
16. Detterbeck F, Kiser A, Detterbeck FC, et al: Anonymous diagnosis and treatment of lung cancer. In An evidence-based guide for practicing clinicians. Edited by: Detterbeck FC, Rivera MP, Siocinski MA, et al. Philadelphia: Saunders; 2001:

17. Langendijk JA, Tjwa MK, de Jong JM, et al: Massive haemoptysis after radiotherapy in inoperable non-small cell lung carcinoma: is endobronchial bracytherapy really a risk factor? Radiother Oncol 1998, 49(2):175-183.

18. Phillips TL, Wharam MD, Margolis LW: Modification of radiation injury to normal tissue by chemotherapeutic agents. Cancer 1975, 35:1678-1684.

19. Chaudhuri MR: Primary pulmonary cavitating carcinomas. Thorax 1973, 28(3):354-366.

20. Semenza GL: Hypoxia-induced factor 1: master regulator of $\mathrm{O} 2$ homeostasis. Curr Opin Genet Dev 1998, 8(5):588-594.

21. Johnson DH, Fehrenbacher L, Novotny WF, et al: Randomized phase II trial comparing bevacizumab plus carboplatin and paclitaxel with carboplatin and paclitaxel alone in previously untreated locally advanced or metastatic non-small-cell lung cancer. J Clin Oncol 2004, 22:2184-2191.

22. Sandler A, Gray R, Perry MC, et al: Paclitaxel-carboplatin alone or with bevacizumab for non-small-cell lung cancer. N Engl J Med 2006, 355(24):2542-2550, Erratum in: N Engl J Med, 2007, 356(3):318.

23. Rossi A, Maione P, Gridelli C: Cetuximab in advanced non-small cell lung cancer. Crit Rev Oncol Hematol 2006, 59:139-149.

24. Uflacker $\mathrm{R}$, Kaemmerer A, Picon PD, et al: Bronchial artery embolization in the management of hemoptysis: technical aspects and long-term results. Radiology 1985, 157(3):637-644.

25. Rabkin JE, Astafjef VI, Gothman LN, et al: Transcatheter embolization in the management of pulmonary hemorrhage. Radiology 1987, 163(2):361-365.

26. Knott-Craig CJ, Oostuizen JG, Rossouw G, et al: Management and prognosis of massive hemoptysis. Recent experience with 120 patients. $J$ Thorac Cardiovasc Surg 1993, 105(3):394-397.

27. Ramakantan R, Bandekar VG, Gandhi MS, et al: Radiology. Massive hemoptysis due to pulmonary tuberculosis: control with bronchial artery embolization. Radiology 1996, 200(3):691-694.

28. Fernando $H C$, Stein $M$, Benfield JR, et al: Role of bronchial artery embolization in the management of hemoptysis. Arch Surg 1998, 133(8):862-866.

29. Mal H, Rullon I, Mellot F, et al: Immediate and long-term results of bronchial artery embolization for life-threatening hemoptysis. Chest 1999, 115(4):996-1001.

30. Swanson $\mathrm{KL}$, Johnson $\mathrm{CM}$, Prakash $\mathrm{UB}$, et al: Bronchial artery embolization: experience with 54 patients. Chest 2002, 121(3):789-795.

31. Yu-Tang Goh P, Lin M, Teo N, et al: Embolization for hemoptysis: a sixyear review. Cardiovasc Intervent Radiol 2002, 25(1):17-25, Epub 2001 Nov 23.

32. Witt Ch, Schmidt B, Geisler A, et al: Value of bronchial artery embolisation with platinum coils in timorous pulmonary bleeding. Eur J Cancer 2000, 36(15):1949-1954.

33. Wong ML, Szkup P, Hopley MJ: Percutaneous embolotherapy for lifethreatening hemoptysis. Chest 2002, 121(1):95-102.

\section{Pre-publication history}

The pre-publication history for this paper can be accessed here: http://www.biomedcentral.com/1471-2407/12/27/prepub

doi:10.1186/1471-2407-12-27

Cite this article as: Ito et al:: Risk factors associated with fatal pulmonary hemorrhage in locally advanced non-small cell lung cancer treated with chemoradiotherapy. BMC Cancer 2012 12:27. 